Bergien, Rüdiger, Pröve, Ralf, Spießer, Patrioten, Revolutionäre. Militärische Mobilisierung und gesellschaftliche Ordnung in der Neuzeit

\title{
Marco Cicchini
}

\section{(2) OpenEdition}

\section{Journals}

Édition électronique

URL : http://journals.openedition.org/ifha/6555

DOI : $10.4000 /$ ifha. 6555

ISSN : 2198-8943

Éditeur

IFRA - Institut franco-allemand (sciences historiques et sociales)

Référence électronique

Marco Cicchini, « Bergien, Rüdiger, Pröve, Ralf, Spießer, Patrioten, Revolutionäre. Militärische Mobilisierung und gesellschaftliche Ordnung in der Neuzeit », Revue de l'IFHA [En ligne], Date de recension, mis en ligne le 01 janvier 2011, consulté le 22 septembre 2020. URL : http://journals.openedition.org/ ifha/6555; DOI : https://doi.org/10.4000/ifha.6555

Ce document a été généré automatiquement le 22 septembre 2020.

(CIFHA 


\title{
Bergien, Rüdiger, Pröve, Ralf, Spießer, Patrioten, Revolutionäre. Militärische Mobilisierung und gesellschaftliche Ordnung in der Neuzeit
}

\author{
Marco Cicchini
}

1 Sous l'impulsion de la sociologie historique, la plupart des études du fait militaire s'attachent depuis une trentaine d'années à montrer les liens étroits que le phénomène entretient avec la genèse de l'État moderne, à indexer le développement des armées permanentes en Europe et leur étatisation sur l'affirmation de la puissance publique. Sans se départir de cet arrière-fond théorique puissant, R.B. et R.P. proposent de poser les jalons d'un champ relativement neuf consacré à la mobilisation militaire des nonmilitaires. Les enjeux d'un tel chantier ne sont pas minces, car au-delà de l'affirmation de principe sur la confiscation progressive des moyens militaires par l'État, les études consacrées aux pratiques sociales - acceptation ou résistance - et aux manifestations concrètes du monopole de la violence physique légitime sont encore trop rares.

2 Faisant suite à une journée d'études tenue en 2008 à l'université de Potsdam, ce livre réunit 18 contributions aussi riches qu'hétérogènes du point de vue thématique. L'étude de l'engagement militaire hors des structures armées, comme le montrent les directeurs de la publication dans une introduction volontairement programmatique, nourrit nombre de pistes de recherches, notamment en rapport à la légitimité du pouvoir établi, aux formes de la régulation sociale, aux conditions de la participation politique. Si le spectre chronologique des travaux ici rassemblés s'étend du XVIe au XXe siècle, le sens de la mobilisation des non-militaires varie fortement selon les époques et les lieux, puisqu'il dépend avant tout de la force de l'armée régulière, voire de la distinction même entre « civils » et " militaires ». La définition du volontariat 
armé se trouve ainsi revisitée en fonction de référents pour l'action et de motifs d'engagement variant fortement selon les contextes et les périodes.

3 Le livre et ses quatre parties thématiques témoignent amplement de la diversité vertigineuse des situations et des cas. La première partie est consacrée à la mobilisation des non-militaires voulue par les pouvoirs publics, telle qu'elle est mise en place par exemple en Hesse-Cassel, entre la fin du XVIe et le début XVIIe siècle, avec l'incorporation des sujets au système de défense du landgraviat (H.T. Gräf). Les deux exemples suivants s'intéressent aux débats complexes sur le système de milice qui secouent aussi bien l'empire austro-hongrois (G. Kronenbitter) que l'empire allemand (O. Stein), tout au long du XIXe siècle et jusqu'en 1914. Deux contributions illustrent ensuite la tension entre armée régulière et formations paramilitaires aux premières heures de la République de Weimar (B. Barth, R. Bergien). Cette section se clôt avec le cas des groupes de combats de la classe ouvrière (Kampfgruppen der Arbeiterklasse) mis en place en RDA dès 1953, avec la bénédiction du Parti socialiste unifié (T. Siebeneichner).

4 La deuxième partie est consacrée à l'expression identitaire - locale ou régionale - de la milice. Les milices Guarani, dans le Paraguay des Jésuites (milieu du XVIIe - milieu du XVIIIe siècle), en fournissent un premier exemple (F. Fechner) qui fait écho aux expériences vécues, à peu près au même moment par les milices urbaines danoises ( $\mathrm{S}$. Bitsch Christensen) ou par les milices territoriales brandebourgeoises (F. Göse). Dans les trois cas, la monarchie et la montée en puissance de l'absolutisme s'affirment de manière subtile, souvent en tirant bénéfice de l'expérience milicienne et non pas en l'éradiquant purement et simplement. Comme le montre l'exemple des milices bourgeoises de Fribourg en Breisgau au moment des guerres de la Révolution française, celles-ci s'érigent en étendard du patriotisme germanique (U. Planert).

5 La troisième partie traite de la mobilisation militaire révolutionnaire. Erigée contre le statu quo et portée par la passion de la liberté, cette forme de mobilisation rompt volontiers avec les dynamiques de recrutement antérieures, comme dans le cas des Gardes nationales de la Révolution française (W. Kruse). À l'inverse, dans des situations de résistance, les traditions culturelles ancestrales sont convoquées, comme le montre l'engagement antinapoléonien dans les territoires sous domination espagnole (L. Pelizaeus) ou le cas des milices paramilitaires polonaises à la fin de la Première Guerre mondiale (P.J. Wróbel). Le dernier cas examiné dans cette section, consacré à la Rote Armee Fraktion (J. Hürter), pose la question de l'identité du groupe des engagés, entre entité politico-militaire revendiquée et assignation au statut d'organisation criminelle et terroriste.

6 La dernière partie s'attache aux représentations de la milice et à la définition du milicien. Depuis le XVIe siècle, les débats sur les contours de l'organisation armée produisent des discours en creux, mais fondamentaux, sur la Cité. C'est ce que montre aussi bien la question de la participation des juifs au devoir militaire à l'époque moderne (B.A. Tlusty), que la circulation du modèle helvétique de milice parmi les hérauts du mouvement socialiste - Liebknecht, Jaurès (R. Jaun). Les deux dernières contributions, sur le rapport entre guerre mondiale et mobilisation civile (F. Reichherzer), ainsi que sur l'idée de milice dans l'Allemagne post-1945 (M. Rink), réactualisent la question de manière contrastée, entre menace de guerre totale et obsolescence de la figure du citoyen-soldat.

$7 \quad$ Marco Cicchini (université de Genève) 